\title{
A CASE OF ANGIO-GLIOMATOSIS RETINAE WITH PATHOLOGICAL REPORT
}

B Y

\author{
T. Ashdown Carr and H. B. Stallard
}

DERBY

LONDON

WE report the clinical and pathological findings of this case because we believe this condition is relatively rare and presents certain features of unusual interest.

Clinical Notes.-C. M. was born on December 14, 1918, and the medical history of the early part of his life was uneventful till July 21, 1931, when he discovered that the left vision was blurred. Examination of the left eye revealed numerous fine vitreous opacities and a circular white woolly-looking mass situated in the retina and encroaching on the upper temporal quadrant of the optic disc. The diameter of this mass was approximately $3 \mathrm{~mm}$. and the upper temporal branches of the central retinal vessels crossed its anterior surface. The neoplasm obscured the optic disc at the point where the upper temporal branches of the central retinal vessels left the parent trunk. The left vision was $6 / 36$ and the pupil reactions and intra-ocular pressure were normal. There was no clinical evidence of disease in the right eye; the Wassermann reaction was negative; tuberculous disease was searched for both clinically and by X-rays, but this proved negative; the urine was normal and the blood pressure 105/60.

In February, 1932, the left vision was reduced to counting fingers at 3 metres, the white mass had increased in size and was more raised (4-5 dioptres). Fine opacities were noted in the lens and some of the vitreous opacities were larger. General examination and a blood count proved negative. The mass was thought to be inflammatory in nature.

In January, 1933, the mass was much larger and completely obscured the optic disc. The centre of the mass was raised about $i$ dioptres and the margins were blurred and ill-defined. On the nasal side there were two small areas of haemorrhage and crossing its anterior surface were small arteries and veins on their way to and from the temporal part of the fundus. These vessels were partly obscured by the neoplasm at certain points in their course.

This mass was now believed to be a neoplasm and in consultation with $\mathrm{Mr}$. C. H Banford excision was advised and performed on February 15, 1933.

The eye was fixed in Zenker's fluid and divided horizontally. 


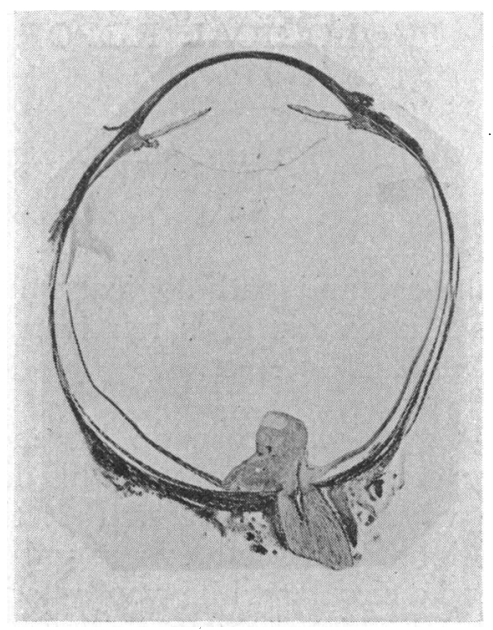

FIG. 1.

Microphotograph to show the neoplasm arising from the retina on the temporal side of the optic disc and overlapping the papilla.

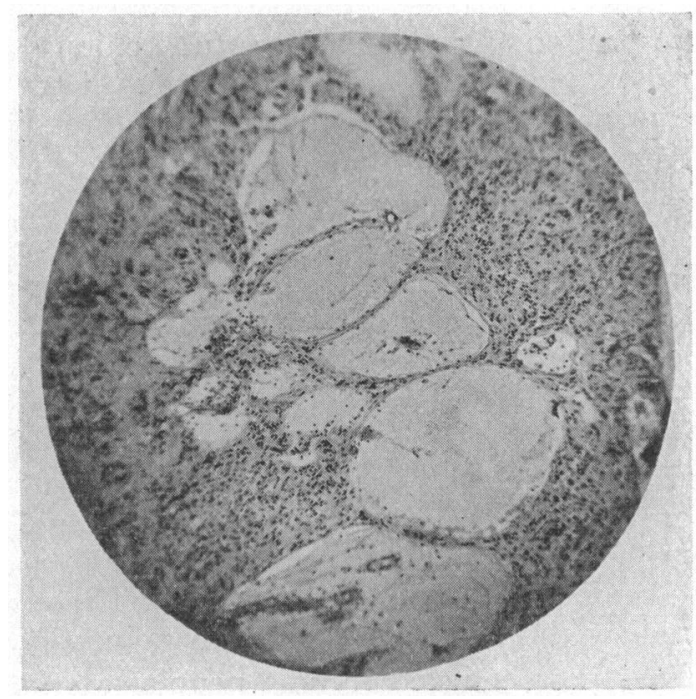

FIG. 2.

Microphotograph showing cystic spaces in the neoplasm near its summit. 
Pathological Report.-There is a neoplasm arising from the retina to the temporal side of the optic disc and invading the papilla. It is shaped like a collar-stud and the basal diameter is $2.5 \mathrm{~mm}$. and the antero-posterior depth $4.5 \mathrm{~mm}$. It is composed mainly of endothelial cells, arranged in irregular clumps, and of glial tissue. Near the summit of the neoplasm there are several

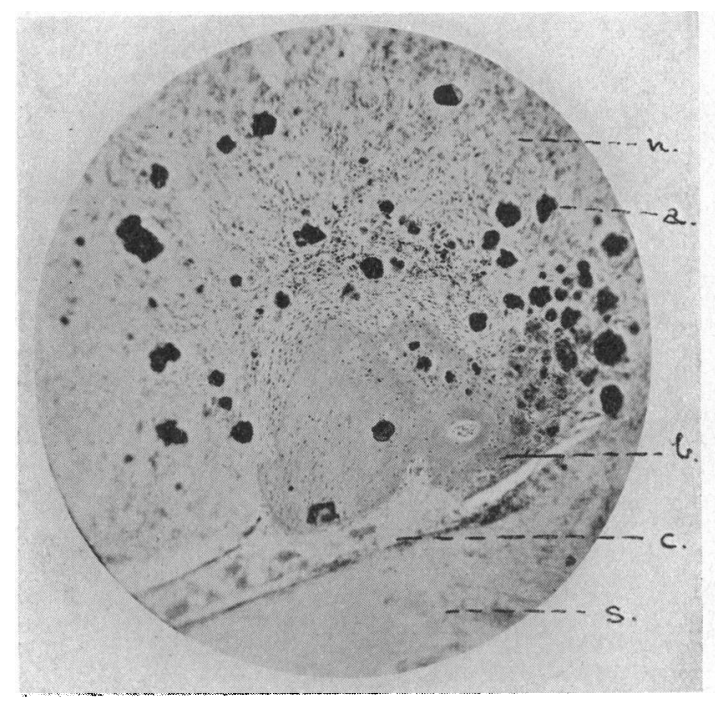

FIG. 3.

Microphotograph to show bone formation and corpora amylacea in the base of the neoplasm and the choroid to the temporal side of the optic disc.
n. Neoplasm.
c. Choroid.
s. Sclera.
b. Bone formation.
a. Amyloid bodies.

cystic spaces filled with granular débris, fibrin, lymphocytes and large mononuclear leucocytes. The walls of these spaces are formed by endothelial cells and glial tissue. Several small capillaries can be seen passing into these areas of cystic degeneration. At the base of the neoplasm there are many amyloid bodies scattered irregularly, and at the temporal edge of the optic disc there is a mass of bone arising from the choroid and passing forwards into the base of the neoplasm. 
The neighbouring retina is rucked up and there is a small collection of sub-retinal fluid producing a shallow localized detachment.

Some punctate deposits of leucocytes are present on the back of the cornea, and the anterior surface of the iris and ligamentum

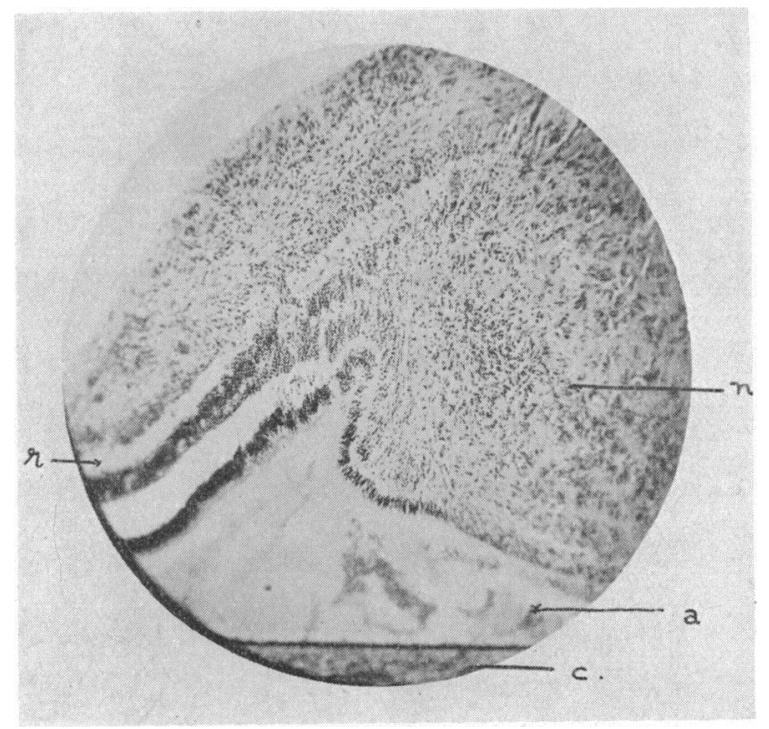

FIG. 4.

This microphotograph shows the temporal edge of the neoplasm infiltrating the retina.

n. Neoplasm.

$r$. Retina, rucked up and detached.

c. Choroid.

a. Sub-retinal fluid.

pectinatum show a plasma cell and lymphocytic infiltration. The remainder of the eye is normal.

There is no evidence of extra-ocular extension of the neoplasm and we believe it is relatively benign.

The diagnosis of angio-gliomatosis with degenerative changes has been made. The points of interest are that no other lesion was found elsewhere in the body on clinical examination, that the neoplasm grew slowly and the histological picture suggested that it possessed a relatively benign character and was even retrogressive in those parts where cystic degeneration, and formation of bone and amyloid bodies had taken place. 